\title{
Reseña bibliográfica: Philp, M. y Escudero, E. (Comps.) (2020). Usos del pasado en la Argentina contemporánea: memorias, instituciones y debates, Córdoba: Edicea, 270 pp.
}

Palabras clave: Usos del pasado - Legitimación del poder - Historia - Memoria

Keywords: Uses of the past - Legitimation of power - History - Memory

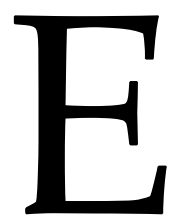

1 libro propone la discusión de un problema clásico: el de la vinculación entre los usos del pasado y la legitimación del poder, es decir, las relaciones entre la historia, la política y la memoria, y las instituciones como espacio de disputa del pasado en nuestro país durante el siglo XX. Pero, sobre todo, se funda en la línea de investigación centrada en los procesos de legitimación política, donde la tradicional historia política es entendida muchas veces como historia del poder. El pasado se convierte en uno de los insumos claves para construir un imaginario conformado por representaciones colectivas, en donde se articulan ideas, imágenes, ritos y modos de acción que varían a lo largo del tiempo en función de las necesidades políticas del presente. Por lo tanto, los usos del pasado, efectuados durante el siglo XX, constituyen un recurso clave en los procesos de legitimación del poder.

La obra condensa doce trabajos, que relacionan los usos del pasado, la historia y la memoria desde distintos abordajes. De este modo, los capítulos se encuentran atravesados por líneas que transitan articulaciones entre los espacios de poder de la memoria, las memorias oficiales, dominantes y hegemónicas. Por esa razón, esto nos permite adentrarnos en el estudio del pasado no solo entendido como memoria del poder, sino también como intentos de explicación de los procesos sociales y de sus condiciones de producción.

El primer capítulo está escrito por Denise Reyna Berrotarán. Este busca establecer los vínculos entre la producción historiográfica de Pablo Cabrera, la creación del Instituto de Estudios Americanistas, los sucesivos intentos de institucionalización de la historia y los consecuentes espacios de investigación y formación que surgieron a posteriori de su creación. Reyna Berrotarán considera que los nuevos institutos y archivos buscaron rápidamente alinear sus producciones detrás de una tradición historiográfica que tomó a Cabrera como mito de los orígenes, aferrándose de ese modo a un historiador con un vasto reconocimiento que permitiera legitimar sus prácticas. 
En el capítulo segundo, Daniel Guzmán nos invita a conocer la circulación del marxismo en la provincia de Santiago del Estero a partir de la vida y obra de dos activistas socialistas de la provincia, como fueron Samuel Yussem y Bernardo Irurzun. El autor indaga sobre la producción y circulación de textos e ideas vinculados a la obra de Karl Marx y a la influencia de la Revolución Rusa en dos centros marxistas de Santiago del Estero: uno en la capital y el otro en las Termas de Río Hondo, reconstruyendo la influencia del marxismo y su relectura para la interpretación de la historia en clave local.

En el tercer capítulo, Agustín Rojas realiza un análisis de los diversos impulsos institucionales y representaciones conceptuales para exponer algunos prejuicios arraigados, como la visión "porteñocéntrica" muy común en las representaciones sobre el pasado. Sin perder de vista la tensión simbólica entre nación y provincias que recorre casi toda la historiografía argentina, Rojas da cuenta de que los relatos interioranos, en muchas ocasiones, han logrado penetrar eficientemente dentro de los principales centros intelectuales del país.

En el cuarto capítulo, Diego Naselli retoma la figura de Roberto Levillier, diplomático e historiador delegado en 1934 ante la Asamblea de la Sociedad de Naciones (1934), y realiza un análisis de las conferencias brindadas por este en España en 1935, donde Levillier reivindica la conquista del Imperio español sobre América. A lo largo del capítulo, el autor irá reconstruyendo el pensamiento de esta figura centrado en las preocupaciones por recuperar los valores culturales de la colonización española.

Los siguientes dos capítulos se refieren a sendos historiadores de la provincia de Córdoba con proyección nacional, vinculados a instituciones importantes como la Universidad Nacional de Córdoba en el siglo XX.

En el quinto capítulo, una de las compiladoras, Marta Philp, analiza los vínculos entre la historia, la política y la memoria en los años 70, advirtiendo la necesidad de buscar una mirada de larga duración, que nos permita conocer las trayectorias de vida, las opciones ideológicas que guiaron las lecturas del pasado plasmadas en textos sobre la historia de Córdoba. Se centra en la producción de Carlos Luque Colombres, un abogado que escribió historia al mismo tiempo que ocupaba espacios de poder en la Universidad Nacional de Córdoba. Su obra forma parte de una línea historiográfica destinada a resaltar personalidades, localismos, costumbres y curiosidades, descripciones más o menos sintéticas de las tradiciones locales.

El sexto capítulo, de Verónica Canciani Vivanco, trata sobre Efraín Bischoff. Como "custodio de la Historia de Córdoba", Bischoff fue el historiador oficial de la provincia, reconocido ciudadano ilustre de la ciudad de Córdoba y Doctor Honoris Causa de la Universidad Nacional de Córdoba, su obra fue declarada de interés cultural por el gobierno de la provincia. Este trabajo nos permite conocer cómo se invisten determinadas personalidades públicas de autoridad legítima y legitimante sobre la base de un "saber" que le otorga autoridad, pero que es al mismo tiempo autorizante. 
El séptimo capítulo, de Marcelo Guardatti, retoma una vieja discusión entre dos localidades del interior de la provincia de Córdoba, Oncativo y Laguna Larga, referida a la ubicación de dónde fue la histórica batalla del 25 de febrero de 1830, cuando se enfrentaron las fuerzas del unitario general José María Paz y el federal Juan Facundo Quiroga. A lo largo del trabajo, el autor nos muestra que la auténtica disputa aquí no es tanto la verdad histórica, sino, más bien, su apropiación en tanto acontecimiento histórico que le permite a ambas localidades construir su identidad histórica.

En el octavo capítulo, Cristian Celis, a partir de las categorías de "campo" de Pierre Bourdieu, analiza la disputa entre las diferentes concepciones de democracia que subyacían en la discusión de la reforma constitucional de 1949 en la Convención Provincial Constituyente. Más precisamente, el abordaje hace foco en las demandas de la libertad sindical y el derecho a huelga, dos aspectos centrales que evidenciaban la nueva correlación de fuerzas que se configuraba desde el gobierno nacional.

El capítulo noveno corresponde a otro de los compiladores, Eduardo Escudero, quien nos ofrece un interesante análisis de los llamados "museos de la subversión" fundados en los setenta. Allí, el autor da cuenta de las distintas exposiciones de estas características que existieron en el país. Escudero se detiene especialmente en el caso del "Museo de la Lucha contra la Subversión" sito en el III Cuerpo de Ejército. La originalidad radica en la minuciosa descripción que el autor realiza de los objetos que nutrían los museos que dan cuenta, una vez más, de la organización y planificación con la que contó el terrorismo de Estado.

En el décimo capítulo, se encuentra el trabajo de Carolina Favaccio que, desde una línea de investigación centrada en las memorias institucionales en épocas de transiciones, nos ofrece un análisis de la comunidad de docentes y estudiantes de la Escuela de Filosofía de la Universidad Nacional de Córdoba que formaron parte de la etapa de transición de la dictadura a la democracia en los años '80. El capítulo gira en torno a las preocupaciones de docentes y estudiantes en cuanto al legado autoritario recibido en los espacios de poder. Para Favaccio, la disputa por la desarticulación de la herencia dictatorial significó también una disputa por desterrar una determinada concepción de la filosofía.

El décimo primer capítulo es de Gloria Di Rienzo, que realiza un repaso de las claves políticas, sociales y económicas que atravesaron el primer gobierno de la transición, haciendo foco en los tres aspectos centrales: el legado autoritario (entendido en los términos de la violación de los derechos humanos en la última dictadura militar), la crisis económica y, por último, la cuestión sindical (en la voz del peronismo derrotado). En este contexto, la autora intenta indagar en los usos del pasado y la memoria política para establecer qué consensos se construyeron y cuáles quedaron atrás en este año de crisis en la construcción de la ciudadanía, así como las pautas de la legitimación política del nuevo gobierno que asumió anticipadamente.

Finalmente, en el último capítulo Ayelén Brusa indaga acerca de la historia como literatura de lo social y el estudio de los usos del pasado como literatura de lo político. 
A partir de una revisión de los aportes del historiador francés Iván Jablonka, Brusa interroga acerca de la relación y convivencia entre la historia y la literatura, tomando como eje de análisis el conocimiento y planteándose desde donde se produce el mismo.

Se puede observar que cada capítulo es abordado desde diferentes lugares, territorios, memorias, de donde se desprenden diversas aristas que hacen que la lectura no sea lineal, sino, más bien, intermitente, otorgando un particularismo unitario a cada apartado. Alicia Servetto sugiere tomar los trabajos y agruparlos en dos líneas de investigación definidas. Por un lado, aquellos que se detienen en el estudio de cómo el pasado es reconstruido o resignificado, ya sea desde la historia o la memoria, para otorgar legitimidad a un determinado orden político y preocupándose por las distintas resignificaciones del pasado, como fuente indiscutible de legitimación de poder. Y, por otro lado, los trabajos que comprenden aquellos conflictos por el sentido del pasado que se busca reconstruir, que forman parte de la disputa por la interpretación del "pasado en conflicto". Son análisis de lugares, sitios y memorias donde se desatan las luchas y se ponen en escena las diferentes narraciones, de tensiones y rupturas, de silencios y olvidos.

Un aspecto interesante de este libro es la inclusión de egresados y estudiantes, que buscan nuevas formas de mirar al pasado y una narrativa más acorde a los tiempos que corren. Asimismo, no son solo autores de Córdoba capital, el grupo reúne también investigadores del interior de Córdoba, de Santiago del Estero, lo que acentúa el carácter diverso de las miradas que ofrece esta obra. No obstante, a pesar de esa pluralidad de autores, las distintas producciones no pierden de vista la idea central del libro: los usos del pasado.

Además, cabe resaltar que, si bien es un trabajo producido en el ámbito académico de índole científica, el libro está dirigido a un público más amplio, con el fin de divulgar los nuevos trabajos y producciones desarrollados en el seno de la universidad. Por esa razón, se presenta como una obra para ser leída por quienes buscan temas novedosos o poco explorados dentro de temática abordada.

Finalmente, en términos más amplios, considero que la ampliación del campo temático y de las perspectivas de la historia de la historiografía ejemplificados en este libro terminan revelando también la discusión colectiva sobre las cuestiones analizadas en cada capítulo, lo que le da unidad y coherencia.

Juan Manuel Arnaiz

Universidad Nacional del Nordeste juanma_a1@hotmail.com.ar 
Para citar esta reseña:

Arnaiz, Juan Manuel (2021): Reseña bibliográfica, “Philp, M. y Escudero, E. (Comps.) (2020). Usos del pasado en la Argentina contemporánea: memorias, instituciones y debates, Córdoba: Edicea, 270 pp." Anuario de la Escuela de Historia Virtual 19, 163-167. 